\title{
ANNUAL PrEcipitation IN SOUTHERN OF MADAGASCAR: MODELING USING HIGH ORDER FUZZY TIME SERIES
}

\author{
Harimino Andriamalala RAJAONARISOA, Irrish Parker RAMAHAZOSOA, \\ Hery Zojaona Tantely STEFANA ZAFIMARINA REZIKY, Adolphe \\ Andriamanga RATIARISON
}

\begin{abstract}
Atmosphere, Climate and Oceans Dynamics Laboratory (DyACO), Physics and Applications, Sciences and Technology Domain, University of Antananarivo, Antananarivo, Madagascar
\end{abstract}

\begin{abstract}
The objective of this research is to find the best conventional high order fuzzy time series model for annual precipitation series in southern Madagascar. This work consists on finding the hyper parameters (number of partition of the universe of discourse and model order) to obtain the best conventional high order fuzzy time series model for our experimental data. In previous works, entitled spatial and temporal variability of precipitation in southern Madagascar, we subdivided the study area between $22^{\circ} \mathrm{S}$ to $30^{\circ} \mathrm{S}$ latitude and $43^{\circ}$ Eto $48^{\circ}$ E longitude into four zones of homogeneous precipitation. In this article, we seek to model annual precipitation data representative of one of these four areas. These data were taken between 1979 and 2017. Our approach consists on subdividing the data: data obtained from 1979 to 2001 (60\%) for the training and data from 2002 to 2017 (40\%) to test the model. To determine the number of partitions and model order, we fix first the number of partitions to 10 and then to 15, 20, 25,30, 35, 40, 45 and 50. For each of these values, we vary the model order from 1 to 10.Thenwe locate the model order which corresponds to the minimum of the average curve between the Mean Absolute Errors (MAE) between the training data and the test data. Thus, the orders of the candidate model are 2, 3, 5, and 6.The next step is to fix the model order with the previous values and vary the number of partitions from 3 to 50.For each couple of hyper parameter of the model (number of partitions, model order), we locate the value of number of partitions corresponding to the minimum of the average curve between the absolute mean of the errors or MAE (Mean Absolute Error) between the train and test data. We obtain the hyper-parameter pairs (37, 2), (20, 3), (35, 5) and (35, 6).The first pair gives the lowest Mean Absolute Error. As a final result, we obtain the best high order fuzzy time series model with hyper-parameters number of partition equals thirty seven and of order equals two for annual precipitation in Southern of Madagascar
\end{abstract}

\section{KEYWORDS}

High Order Fuzzy Time Series, Mean Absolute Error, Number of Partition, Model order, Precipitation, Southern Madagascar

\section{INTRODUCTION}

Climate change affects human activities around the world. According to the report of the Intergovernmental Panel on Climate Change (IPCC) of October 08, 2018, a warming of $+1.5^{\circ} \mathrm{C}$ or $+2{ }^{\circ} \mathrm{C}$ will change the world. If the warming continues its current rate, it will reach $+.1 .5^{\circ} \mathrm{C}$ between 2030 and 2052 [1].This will have significant consequences on life and economy. Obviously, global warming makes droughts worse. A meteorological type drought, according to the World Meteorological Organization, is defined by a threshold corresponding to a certain 
deficit of precipitation over a determined period of time. The chosen threshold (for example $75 \%$ of normal) and the duration of the period (for example 6 months) vary from one place to another depending on the needs of the user or the applications concerned [2]. Madagascar, like all other countries, is also victim of climate change. In particular, southern Madagascar is prone to the problem of increasing frequency / intensity of drought and chronic water scarcity. This situation leads to serious crises of food insecurity and malnutrition which mainly affect children. According to the UNICEF, drought in the southern part of Madagascar is alarming [3]. The rainfall situation in the Southern region of Madagascar during February 2020 still shows a deficit compared to the normal for that month. The water levels vary from $9.769 \mathrm{~mm}$ to $80.283 \mathrm{~mm}$ with a monthly average of $43.305 \mathrm{~mm}$; the rains remain insufficient compared to the February normal rate [3].

To know how the precipitation evolves in the South of Madagascar is an issue.

Many researchers ([4], [5]) use mathematical theories to predict annual precipitation. They use econometric models such as ARIMA formulated by Box and Jenkins to model the time series of precipitation [6]. In 1993, Song and Chissom invented the theories of fuzzy time series to predict enrollment at the University of Albama [7], [8], [9]. Fuzzy time series is an assembly of fuzzy logic theory invented by Zadeh Lotfi in 1973and time series [10], [11], [12].Several variants of the theory of fuzzy time series have been carried out, namely Chen's method for first order fuzzy time series [13]. Afterwards, the evolution of fuzzy time series comes to the point where the model order can be greater than 1 . The theory on fuzzy time series that we are going to exploit in this paper in the one used by Severiano et al. in 2017, which is a high order fuzzy time series [14].

The aim of this research is to use the conventional high order fuzzy time series model to model annual precipitation in Southern of Madagascar. More precisely, it is a question of determining the hyper parameters number of partition and model order with which we obtain the best modeling.

\section{METHODS}

\subsection{Experimental Data}

We use daily precipitation data, in grid point from January 1, 1979 to December 31, 2017 [15]. In [16], we have regionalized the south of Madagascar (between latitude $22^{\circ} \mathrm{S}$ and $30^{\circ} \mathrm{S}$ and longitude $43^{\circ} \mathrm{E}$ and $48^{\circ} \mathrm{E}$ with a resolution of $1^{\circ} \mathrm{x} 1^{\circ}$ )into four homogeneous precipitation zones. The reason for this regionalization is to classify each zone according to their characters of precipitation for each season. Then we call these zones zone 1, zone 2, zone 3 and zone4. Zone 1 is a zone of weak precipitation in Southern winter. Zone 2 is a zone of weak precipitation in Southern summer. Zone 3 is a zone of heavy precipitation in Southern winter and zone 4 is a zone of heavy precipitation in Southern summer.

The relation between [16] and this paper is that experimental data used in this present work is the annual precipitation data of zone 2in [16], which is an area in extreme Southwest of Madagascar.

Let usrecall the regionalization procedure that we have presented in [16]. We start from daily precipitation data taken in grid points. For each point, we calculate the average of the monthly precipitation accumulation during thirty seven years. The starting array is a 12-dimensional array.The process established for regionalization has four steps: 
Step 1: Reducing the dimension of the data into two dimensions,

Step 2: Visualizing of the individuals in the plan,

Step 3: Grouping of individuals using a clustering method,

Step 4: Evaluation of the classification.

Principal Component Analysis (see [17], [18], [19], [20], [21], [22]) and the t-sne algorithm, that is, a nonlinear algorithm for data size reduction (see [23], [24], [25], [26]) are used for data size reduction. Associated clustering methods are k-Means [27], [28] and Fuzzy C-Means [29], [30], [31], [32], [33], [34], [35]. The Dunn index evaluates each classification obtained[36], [37], [38], [39], [40], [41]. The best regionalization is obtained by using t-sne algorithm (with perplexity parameter 5) followed by Fuzzy C-Means clustering (with parameter $m=1.1$ ). Figure 1 below shows the grid points and the result of regionalization in [16].

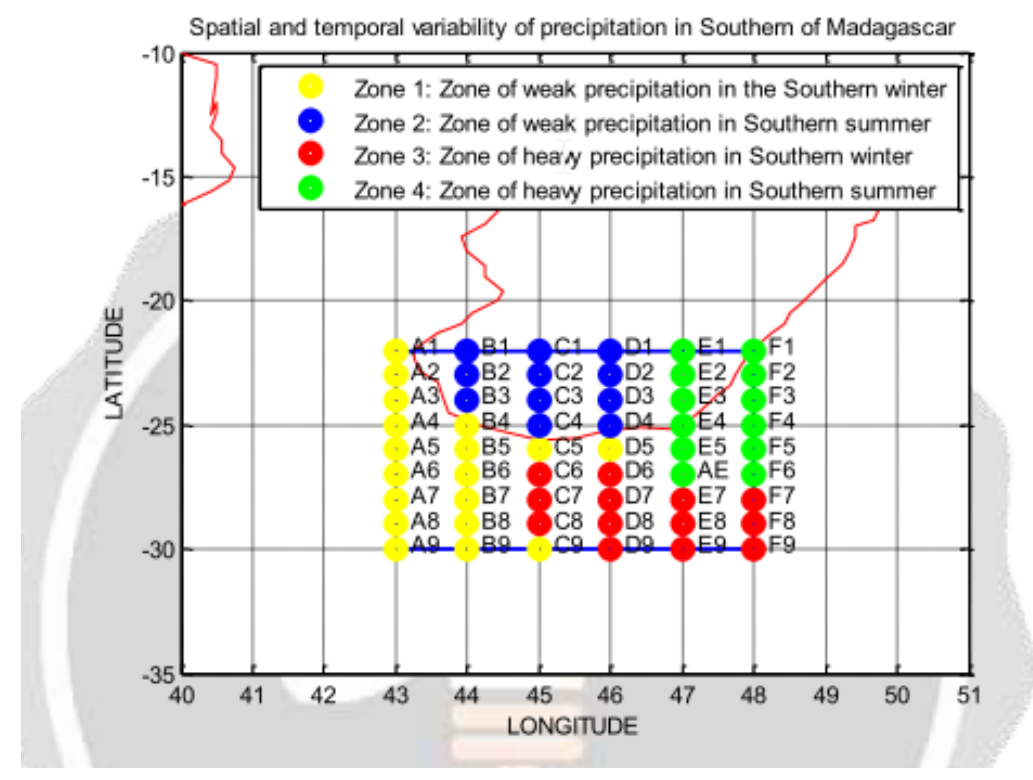

Figure 1. Spatial and temporal variability of precipitation in Southern of Madagascar

Table 1 shows annual precipitation data representativefor the "zone2" in Figure 1.We use datasets in Table 1 to experiment thenew methods that we are going to present in this paper.

Table 1. Annual precipitation (in millimeter).

\begin{tabular}{|c|c|}
\hline Year & Precipitation \\
\hline 1979 & 825.3 \\
\hline 1980 & 740.2 \\
\hline 1981 & 1101.7 \\
\hline 1982 & 1048.7 \\
\hline 1983 & 729.7 \\
\hline 1984 & 1087.0 \\
\hline 1985 & 754.1 \\
\hline 1986 & 947.9 \\
\hline 1987 & 814.1 \\
\hline 1988 & 654.1 \\
\hline 1989 & 1106.4 \\
\hline 1990 & 726.2 \\
\hline 1991 & 655.9 \\
\hline 1992 & 616.9 \\
\hline
\end{tabular}


International Journal of Fuzzy Logic Systems (IJFLS) Vol.10, No.3/4, October 2020

\begin{tabular}{|c|c|}
\hline 1993 & 816.6 \\
\hline 1994 & 1028.4 \\
\hline 1995 & 773.5 \\
\hline 1996 & 855.3 \\
\hline 1997 & 925.5 \\
\hline 1998 & 850.8 \\
\hline 1999 & 890.3 \\
\hline 2000 & 964.9 \\
\hline 2001 & 898.3 \\
\hline 2002 & 776.4 \\
\hline 2003 & 886.6 \\
\hline 2004 & 798.5 \\
\hline 2005 & 722.4 \\
\hline 2006 & 521.8 \\
\hline 2007 & 819.6 \\
\hline 2008 & 703.6 \\
\hline 2009 & 703.5 \\
\hline 2010 & 770.0 \\
\hline 2011 & 952.0 \\
\hline 2012 & 914.2 \\
\hline 2013 & 632.8 \\
\hline 2014 & 736.0 \\
\hline 2015 & 1007.9 \\
\hline 2016 & 656.3 \\
\hline 2017 & 721.7 \\
\hline Mean & 824.0 \\
\hline Minimum & 521.8 \\
\hline Maximum & 1106.4 \\
\hline
\end{tabular}

\subsection{Modelling Approach}

We use the conventional high order fuzzy time series to do the modelling. Time series are composed by series of observations represented by real numbers but fuzzy time series are composed by series of fuzzy sets $\mathrm{F}(\mathrm{t})$. The methodology adopted is divided into five parts:

Part 1: Subdivision of experimental data into training data and test data,

Part 2: Trainingprocess,

Part 3: Forecast process,

Part 4: Selection of the hyper parameters of the best model.

\section{Part 1: Subdivision of experimental data}

The experimental data are subdivided into two groups: training data (60\% are from 1979 to 2001) and test data (40\% are from 2002 to 2017). This subdivision is the best because it allows to test the model with data not yet used during the training. Then, it is straightforward to make an excellent forecast for the model with data already employed during the training. We test the performance of the model with data not yet used during the training process to make the test model more objective.

\section{Part 2: Training process}

The training process is subdivided into three stages. We initialize the hyper parameters of the model to 3 for the number of partitions $(\mathrm{k}=3)$ and to 1 for the model order $(\Omega=1)$. This training process that we are going to present in this section can be found in [42] 
Step 1: Partitioning of the discourseuniverse,

Step 2: Fuzzification,

Step 3: Rules induction.

\section{a) Step 1: Partitioningof the discourse's universe}

\section{Definition of the discourse's universe}

The discourse's universeU is defined as follows:

$$
\mathbf{U}=\left[\min (\mathbf{Y})-\mathbf{D}_{1}, \max (\mathbf{Y})+\mathbf{D}_{2}\right],
$$

where $\mathrm{Y}$ is the time series, that is the annual precipitation series,

$$
\begin{aligned}
& \mathrm{D}_{1}=\min (\mathrm{Y}) \times 0.2, \\
& \mathrm{D}_{2}=\max (\mathrm{Y}) \times 0.2 .
\end{aligned}
$$

$D_{1}$ and $D_{2}$ are used to extrapolate the bounds of the extent of the statistical series. They serve as a safety margin.

\section{Partitioning of the universe of discourse}

Subdivide $\mathrm{U}$ into $\mathrm{k}$ intervals $\mathrm{U}_{\mathrm{i}}(\mathrm{i}=1,2, \ldots, \mathrm{k})$ with midpoints $\mathrm{c}_{\mathrm{i}}$. To determine the length of each interval Ui, we use the partition $\pi$ method. The $\pi$ partition method allows us todivide the discourse's universe $\mathrm{U}$ into $\mathrm{k}$ intervals of the same length. This method is also called Grid Partitionning.

\section{Create thelinguistic variable $\widetilde{A}$}

Linguistic variable $\tilde{A}$ is composed by fuzzy sets $A_{i}$, of support $\mathrm{U}_{\mathrm{i} .} \mu_{A_{i}}$ is the membership function of the fuzzy sets $A_{i}$. We use isosceles triangle functions for membership function. The midpoint of the support of the fuzzy set $A_{i}$ is $\mathrm{c}_{\mathrm{i}}$. The lower bound is $\mathrm{l}_{\mathrm{i}}=\mathrm{c}_{\mathrm{i}-1}$ and the upper bound is $\mathrm{c}_{\mathrm{i}+1}$, $\forall i>0$ et $\mathrm{i}<\mathrm{k}$, and $\mathrm{l}_{0}=\operatorname{minU}, \mathrm{l}_{\mathrm{k}}=\max \mathrm{U}$. Each fuzzy set $A_{i} \in \tilde{A}$ is a linguistic term of the linguistic variable $\tilde{\mathrm{A}}$.

\section{b) Step 2: Fuzzification process}

Fuzzification process is a transformation of the time series $\mathrm{Y}$ into a fuzzy time series $\mathrm{F}$ such that each data point $f(t) \in F$ is a rectangular matrix, with 1 row and $k$ columns, composed by the fuzzy set corresponding to $y(t) \in Y$. Fuzzy values or fuzzy set corresponding to $y(t)$ are linguistic terms Ai $\in \tilde{A}$ such that fuzzy membership is defined by:

$$
f(t)=\left\{A_{i} \mid \mu_{A_{i}}(y(t))>\alpha, \forall A_{i} \in \tilde{A}\right\}
$$

In our case, $\alpha=0$.

\section{c) Step 3: Induction rules}

\section{Generating the temporal patterns}

The fuzzy temporal patterns have the following form: 


$$
\text { Precedent } \rightarrow \text { Consequent }
$$

Precedent and consequent are also called respectively Left Hand Side (LHS) and Right Hand Side (RHS).

More precisely, for a $\Omega$-order model, the fuzzy temporal models are of the form:

$$
A_{i_{1}}, \ldots, A_{i_{\Omega}} \rightarrow A_{j}
$$

where precedents or Left Hand Side (LHS) are

$$
f(t-L(\Omega-1))=A_{i_{1}}, \ldots, f(t-L(0))=A_{i \Omega},
$$

with $L$ is the lag operator.

The consequent (Right Hand Side)is defined by:

$$
f(t+1)=A_{j}
$$

\section{Generate the rule base $M$}

Select all temporal patterns having the same precedent and group its consequent. For a $\Omega$-order model, the rules thus obtained are of the form:

$$
A_{i_{1}}, A_{i_{2}} \ldots, A_{i_{\Omega}} \rightarrow \omega_{j_{1}} A_{j_{1}}, \omega_{j_{2}} A_{j_{2}}, \ldots \text { ( } \omega_{j_{i}}=0 \text { or } 1 \text { according to the case), }
$$

where precedents or Left Hand Sides (LHS) are

$$
f(t-L(\Omega-1))=A_{i_{1}}, f(t-L(\Omega-2))=A_{i_{2}}, \ldots, f(t-L(0))=A_{i_{\Omega}},
$$

and the consequences or Right Hand Side (RHS) is

$$
f(t+1) \in\left\{A_{j_{1}}, A_{j_{2}}, \ldots\right\} .
$$

\section{Part 3: Forecast process}

In this present section, we combine two methods which are fuzzification and defuzification that can be found in [42] and [43] respectively.

The forecasting phase is subdivided into three stages:

Step 1: Fuzzification,

Step 2: Rule matching,

Step 3: Defuzzification.

\section{a) Step 1: Fuzzification [42]}

The fuzzification consists to compute, for eachy $(t) \in Y$, the membership grade $\mu_{t_{i}}$ for each fuzzy set $A_{i} \in \tilde{A}$, such that:

$$
\mu_{t_{i}}=\mu_{A_{i}}(y(t))
$$




\section{b) Step 2: Rule matching [42]}

Select the rules where all fuzzy sets $A_{i}$ on the LHS have $\mu_{t_{i}}>0$.

\section{c) Step 3: defuzzification [43]}

Defuzzification is the reverse of fuzzification. That means converting $f(t+1)$ into a real number that corresponds to the forecast value at horizon $\mathrm{h}=1$.If the rule in question is of the form:

$$
A_{i_{1}}, \ldots, A_{i_{\Omega}} \rightarrow A_{j_{0}}, A_{j_{2}}, \ldots A_{j_{m}}
$$

Then the predicted value at time $t+1$ is

$$
\text { Forecast }(t+1)=R V(t)+F V a r,
$$

where $R V(t)$ is the real value of precipitation at time $t$,

$$
F V a r=\frac{\sum_{i=0}^{m} m_{j_{i}}}{m}-m_{i_{\Omega}}
$$

where $m_{j_{i}}$ denotes the midpoint of the interval called the support of the fuzzy set $A_{j_{i}}$ noted supp $\left(A_{j_{i}}\right)$.

Note that

$$
\operatorname{Supp}\left(A_{j_{i}}\right)=\left\{u \in U, \mu_{A_{j_{i}}}(u)>0\right\} .
$$

\section{Part 4: Selection of the hyper parameters of the best model}

The hyper parameters of the model to be determined are the number of partitions $\mathrm{k}$ and the order of the model $\Omega$ with which we obtain the best model. The approach we adopted to find these hyper parameters takes place in three stages:

Step 1: Fix the number of partitions to $10,15,20,25,30,35.40,45,50$ and vary the order of the pattern from 1 to 10 .

Step 2: For each pair of hyper parameter number of partition and order from step 1, calculate the predictions for the train data and test the model with the test data. Then compute the Mean Absolute Error (MAE) between forecast and observation for the train data and the test data. Then take the average between the training MAE and the test MAE.

$$
M A E=\frac{1}{n} \sum_{i=1}^{n}\left|Y_{i}-\widetilde{Y}_{l}\right|,
$$

where

$$
\begin{aligned}
& Y_{i} \text { is the observation, } \\
& \widetilde{Y}_{l} \text { is the forecast, } \\
& \mathrm{n}: \text { is the number of observations. }
\end{aligned}
$$

Step 3: For each pair of hyper-parameter from step 1, determine the order of the model corresponding to the minimum average MAE between training and test.

Step 4: With the values of the order of the model obtained in step 3, vary the number of partitions from 3 to 50 . Then repeat the analogous process of step 2 . 
Step 5: For each pair of hyper-parameter from step 4, determine the number of partitions that correspond to the minimum average MAE between training and test.

Step 6: Among the hyper-parameter couples from step 5, take as the partition number and order of the optimal model the couple that corresponds to the minimum average MAE between training and test.

\section{RESULTS AND INTERPRETATIONS}

Table 2 below summarizes the results of the step 2 that we have mentioned before in the part 4 . The operation consists of successively setting the number of partitions from 10 to 50 in steps of 5 and varying the order of the model from 1 to 10 . For the rest, the values of the order of the model taken into consideration are 2, 3,5,6. We note that as the order of the model increases, the MAE decreases for the training data only.

Table 2: Summary of the results of step 2 of part 4

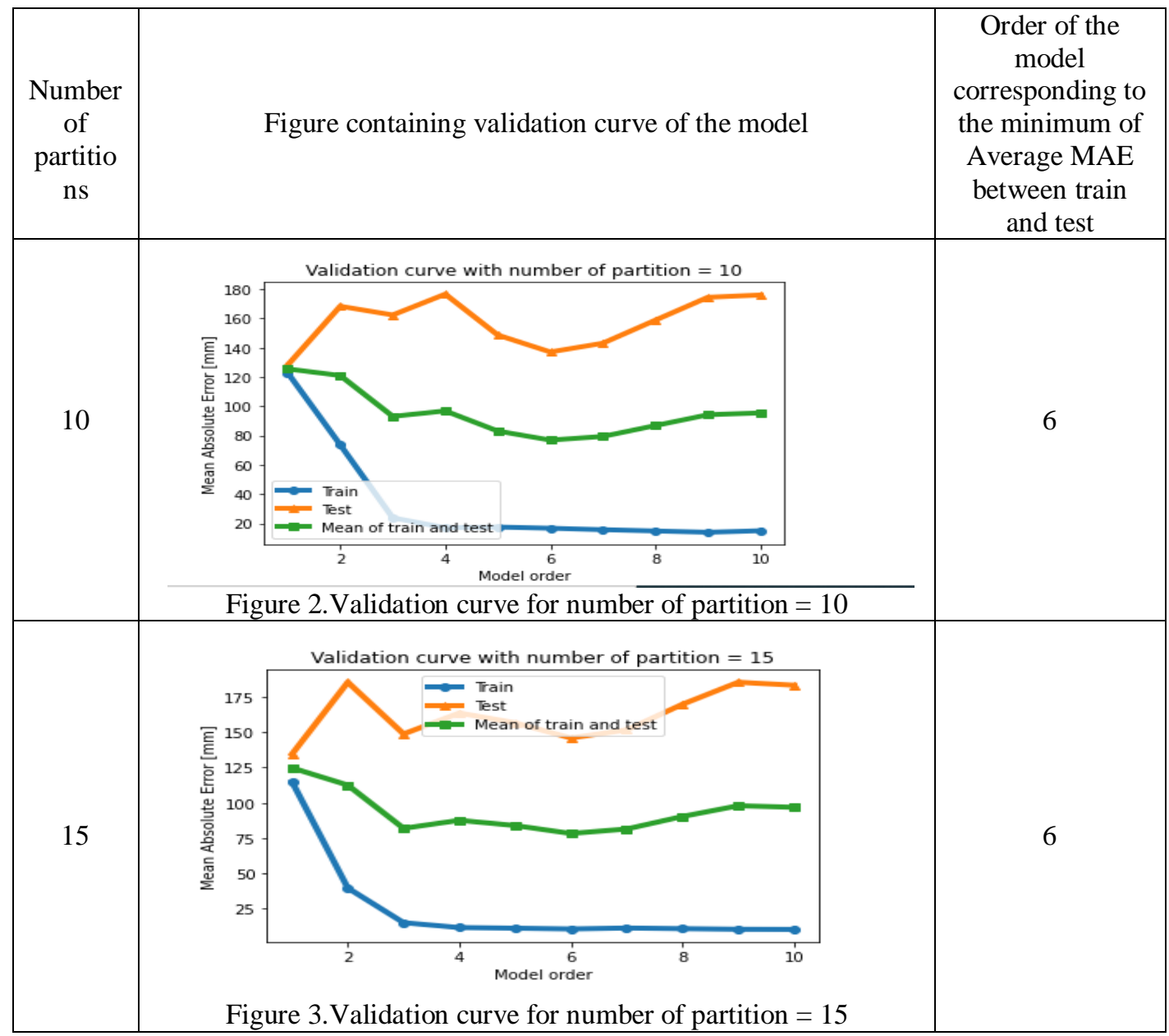


International Journal of Fuzzy Logic Systems (IJFLS) Vol.10, No.3/4, October 2020

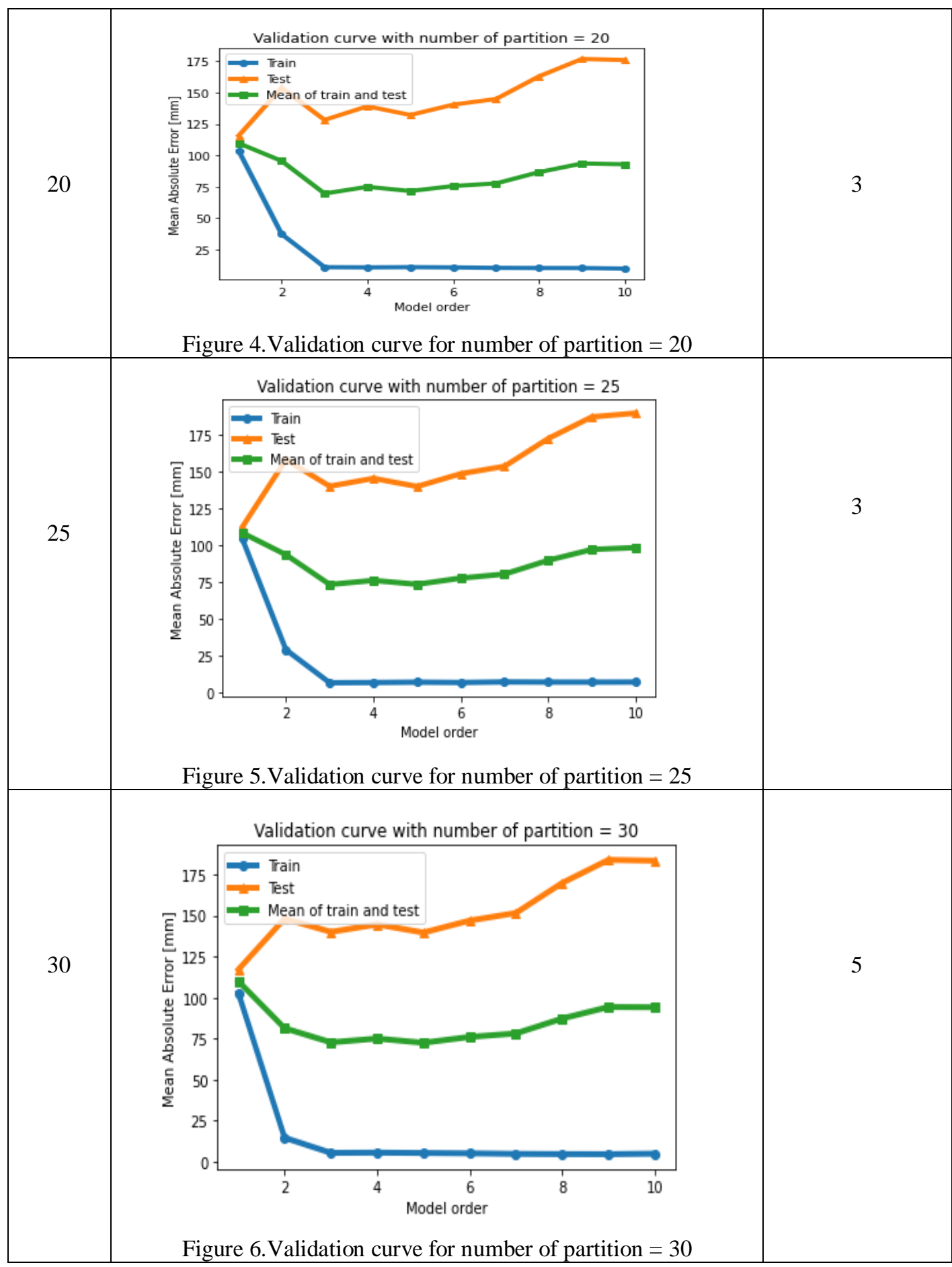


International Journal of Fuzzy Logic Systems (IJFLS) Vol.10, No.3/4, October 2020

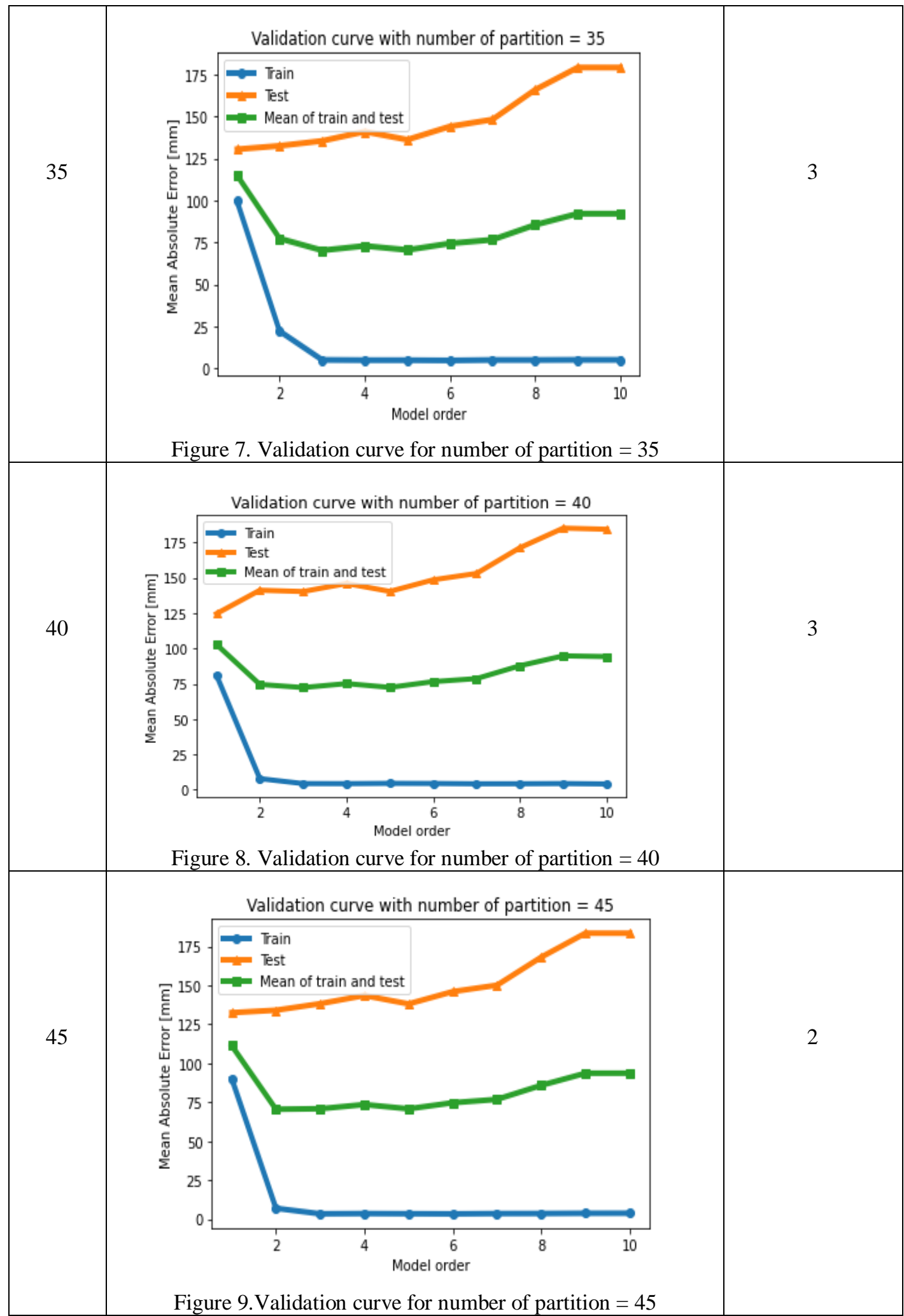


International Journal of Fuzzy Logic Systems (IJFLS) Vol.10, No.3/4, October 2020

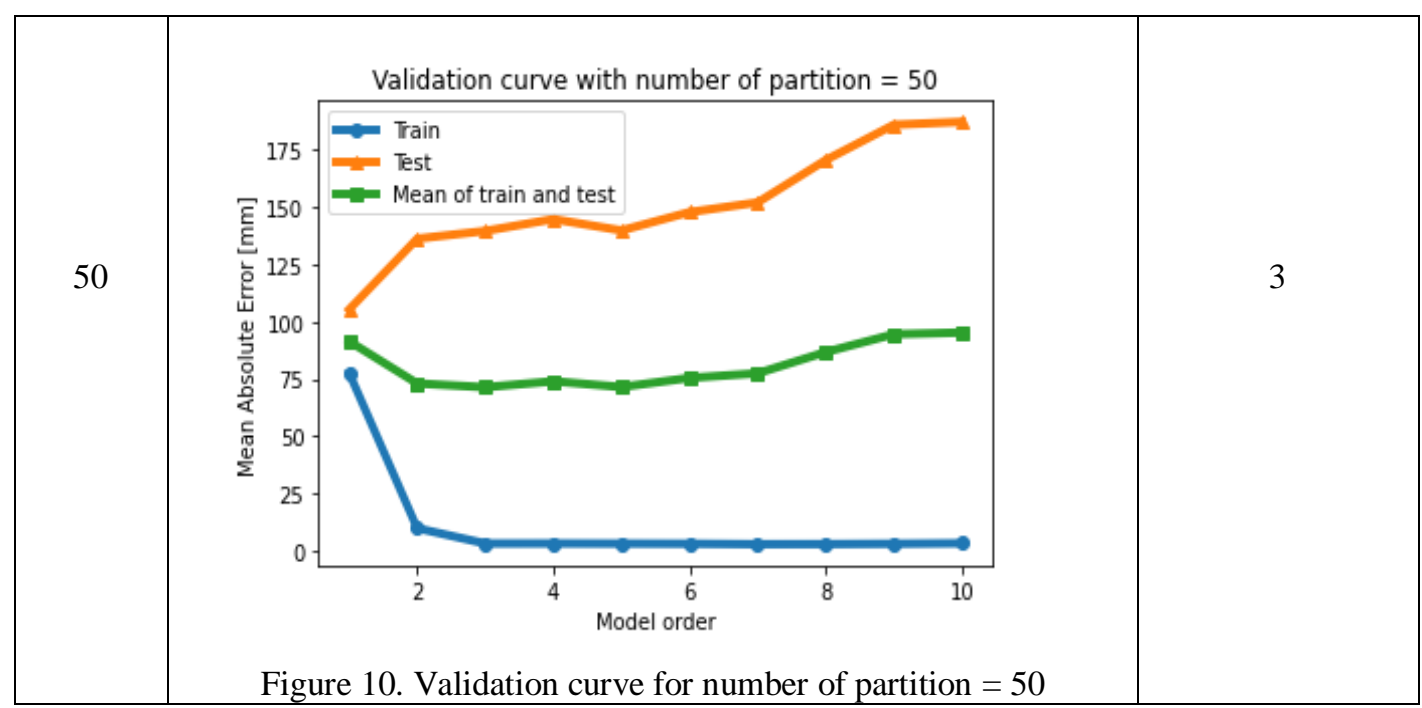

Table 3 below summarizes the results of step 5 of part 4 . This is to fix the order of the model and vary the number of partitions from 3 to 50 . The more the number of partitions increases, the more the MAE decreases for the training data. Whether for the training data or for the test data, the trend of the MAE is asymptotically horizontal.

Table 3: Summary of the results of step 5 of part 4

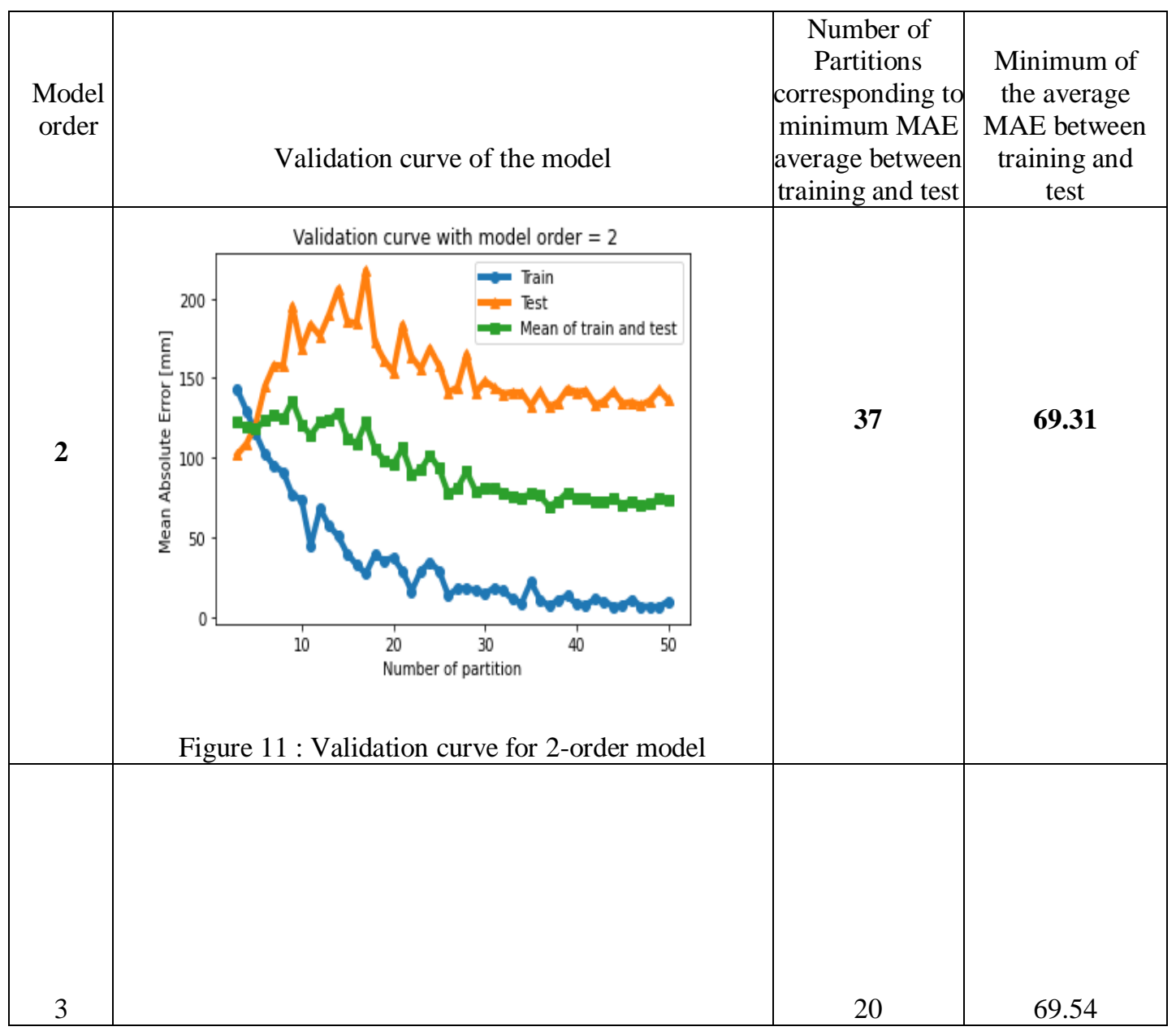


International Journal of Fuzzy Logic Systems (IJFLS) Vol.10, No.3/4, October 2020

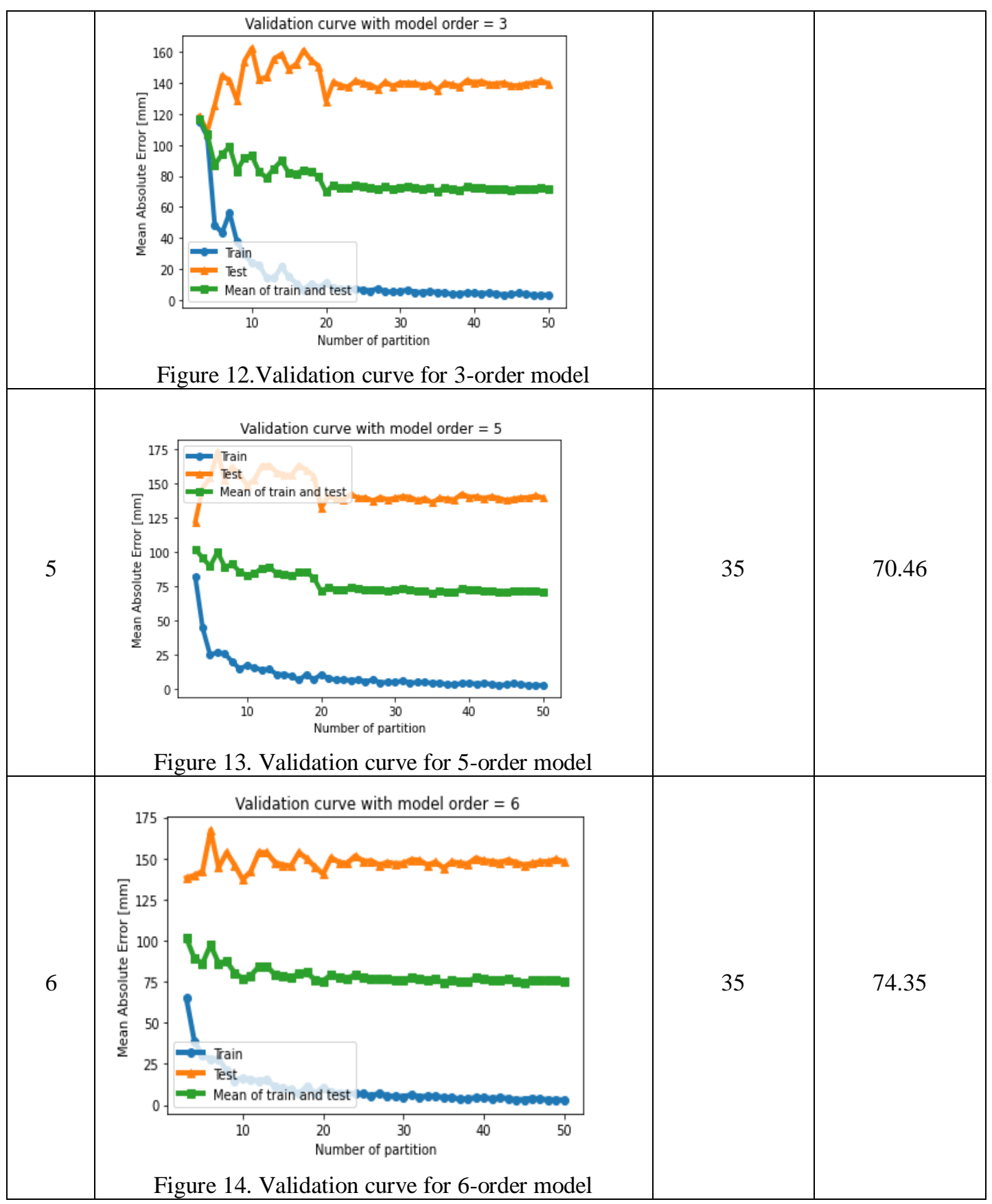

Step 6 of part 4 consists in selecting the hyper parameter pair that corresponds to the minimum average MAE between learning and the test in the table below. We retain the 2-order model with 37 partitions.

Figure 15 below shows the result of the precipitation modeling in southern Madagascar with the fuzzy time series model with hyper parameters number of partition equals 37 and order equals 2 . In green, we have the annual precipitation data observed between 1979 and 2017. In blue we have the modeling of the training data and in yellow the modeling of the test data. Visually, the curves are almost identical. 


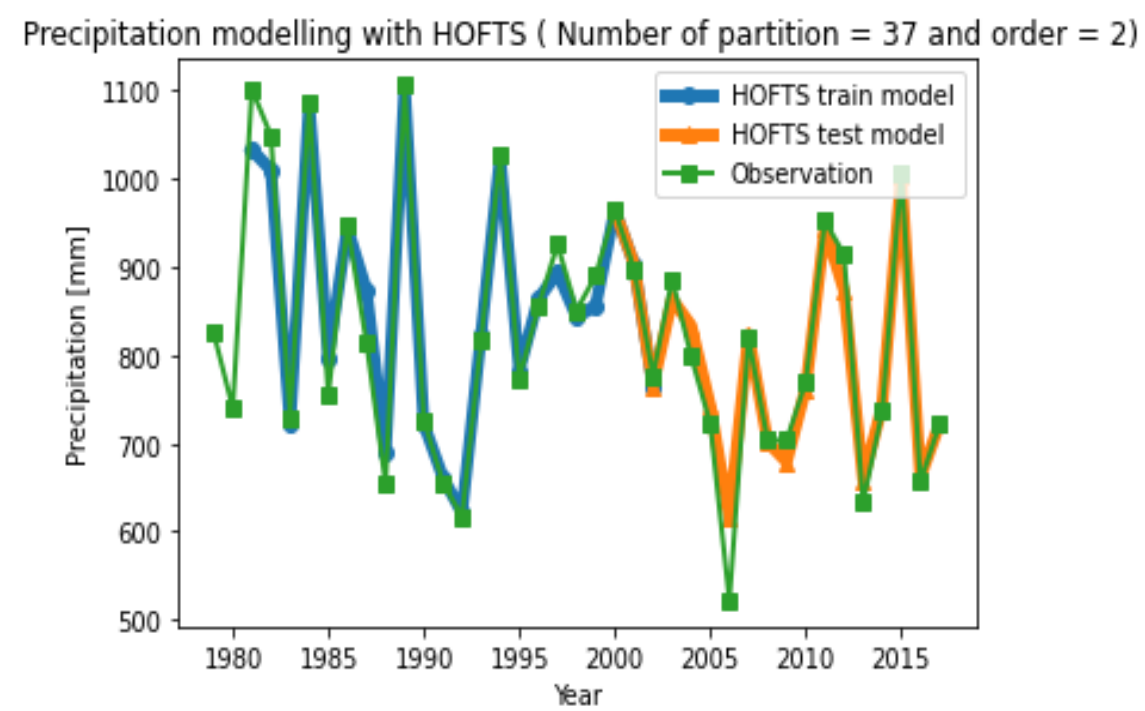

Figure 15. Result of the modeling of precipitation by fuzzy time series (number of partition $=37$ and order $=2$ ).

\section{DISCUSSIONS}

We use the high order fuzzy time series to model the annual precipitation in southern Madagascar. We subdivided the observational data into training data $(60 \%)$ and test data (40\%).The number of partitions and the model order are the two hyper parameters of the model to be determined. To each pair of partition number and order corresponds a forecast model.First, we successively fix the number of partitions from 10 to 50 in steps of 5 and vary the order of the model from 1 to 10 for the training data and the test data. The values of the model order $(2,3,5$, 6) corresponding to the minimum of average MAE between training and testing are selected. Secondly, we fixed the model order with the values found previously and vary the number of partitions from 3 to 50 . The partition number values $(20,35,37)$ corresponding to the minimum average MAE between training and testing are selected. Thus, among the hyper parameter couples considered, the 2-order model with 37 partitions gives the lowest value of MAE. We therefore assume that we have the best modeling of the annual precipitation series in southern of Madagascar with the high order fuzzy time series with hyper parameters number of partitions equals 37 and model order equals 2. Compared with the observation data, the forecast from this model is excellent because visually, the two curves are almost confused with both the training data and the test data.

In the framework of our study, we only used the "grid partitioning" method to subdivide the universe of speech $U$ and create the fuzzy sets [44]. Other researchers in the field use other partitioning methods namely "Entropy partitioner", "FCM partitioner" [45], [46]. The fuzzy sets we have created have triangle membership functions. But there are also researchers who use trapezoidal or Gaussian functions [45].

We used the holistic method for the fuzzification. We consider all the possible linguistic variables with a real variable. On the other hand, in other versions of fuzzy time series as the work of Chen in 1996, during fuzzification, only the linguistic variable with the highest degree of belonging is considered [13]. With this last method of fuzzification, the number of fuzzy rules obtained after the training phase decreases. This gives much more chance of occurrence of cases where the fuzzification of the input data of the model does not correspond to any fuzzy rule. So the holistic method that we used is more interesting. 
There are also other defuzzification methods that researchers use in another version of fuzzy time series modeling (eg Hsuan-Shih Lee \& Ming-Tao Chou [47]).

We use the MAE metric to assess the resulting model contingencies. Note that there are also other metrics to assess the gap between forecast and observation such as RMSE, MSE, MAPE, etc.

Moreover, the work of Petrônio has shown that among the hyper parameters of fuzzy time series models, the number of partition and model order represent $90 \%$ of the accuracy of the model [48].

The singularity of our work lies in the method of determining the hyper parameters partition number and model order : subdivision of the data into training data and test data and setting of a hyper parameter by varying the other and vice versa.

\section{Conclusion}

In this paper, we invent a new method for determining the hyper parameters partition number and model order of conventional high order fuzzy time series models. The method consists of subdividing the data into training data and test data. Fixing the first hyper parameter and varying the second and evaluating the models obtained then fixing the second hyper parameter and varying the first. The model with the lowest MAE valuebetween training and testing is retained. Applied to annual precipitation data in the South of Madagascar, this new method gives the hyper parameters partition number 37 and order equals 2 for the best modeling. The graphical representations of the observed and predicted data with the best model show quasi-juxtaposition both for training and for testing the model.

\section{REFERENCES}

[1] GIEC, (2018), “Approbation par les gouvernements du Résumé à l'intention des décideurs relatif au Rapport spécial du GIEC sur les conséquences d'un réchauffement planétaire de $1,5{ }^{\circ} \mathrm{C}$ ", Communiqué de presse du GIEC, $\mathrm{N}^{\circ} 2018 / 24 / \mathrm{PR}$ retrieved from https://www.ipcc.ch/site/assets/uploads/2018/11/pr_181008_P48_spm_fr.pdf

[2] OMM, (2006), "Suivi de la sécheresse et alerte précoce : principes, progrès et enjeux futures",

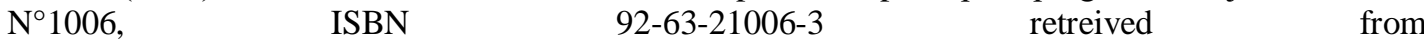
http://www.wamis.org/agm/pubs/brochures/wmo1006fr.pdf

[3] UNICEF, (2020), "Bulletin de monitoring de la sécheresse dans le grand Sud de Madagascar", Bulletin $\mathrm{n}^{\circ} 16$ du 21 Février 2020 au 20 Mars 2020, retrieved from https://www.unicef.org/madagascar/media/2816/file/Bulletin\%20WASH\%20s\%C3\%A9cheresse $\% 20$ -\%20Num\%C3\%A9ro\%2016-\%20Mars\%202020\%20.pdf

[4] Belkacem Balah, (2018), "Frontières d'utilisation de la prévision des pluies mensuelles avec le modèle ARIMA en agriculture", ler Séminaire International Agriculture 4.0: Le Génie Rural au service de l'Environnement, Alger, Algérie. hal-01895012, retrieved from https://hal.archivesouvertes.fr/hal-01895012/document

[5] Belkacem, Balah, (2019), "Modélisation de la prévision des pluies du bassin de la Seybouse avec ARIMA utilisant l'auto-régression et les moyennes mobiles", Conference paper, Retrieved from https://www.researchgate.net/publication/341255392_Modelisation_de_la_prevision_des_pluies_du_ bassin_de_la_Seybouse_avec_ARIMA_utilisant_l'auto-regression_et_les_moyennes _mobiles/link 15eb5bfb9a6fdcc1f1dcae392/download

[6] Shumway, R. H., \& Stoffer, D. S, (2017), "Time series analysis and its applications: with R examples",Springer, retrieved from https://www.stat.pitt.edu/stoffer/tsa4/tsa4.pdf

[7] Q. Song and B.S. Chissom, (1993), "Forecasting enrollments with fuzzy time series - part I", Fuzzy Sets and Systems, Vol. 54, pp 1- 9. 
[8] Lee, H. S., \& Chou, M. T, (2004), “Fuzzy forecasting based on fuzzy time series”,International Journal of Computer Mathematics, 81(7), 781-789.

[9] Saxena, P., Sharma, K., \& Easo, S, (2012), "Forecasting enrollments based on fuzzy time series with higher forecast accuracy rate". Int. J. Computer Technology\& Applications, 3(3), 957-961.

[10] Zadeh, L. A. (1965), "Fuzzy sets", Information and Control, Vol. 8, pp 338-353.

[11] Yun, J., Seo, J. W., \& Yoon, T, (2014), "Fuzzy decision tree". International Journal of Fuzzy Logic Systems (IJFLS), 4(3).

[12] Sudharsan, S., \& Ezhilmaran, D, (2014), "Two new operator defined over interval valued intuitionistic fuzzy sets". International Journal of Fuzzy Logic Systems, 4(4), 1-13.

[13] Sah, M., \& Konstantin Y, D, (2005), "Forecasting enrollment model based on first-order fuzzy time series". In World Academy of Science, Engineering and Technology, 1, 375-378.

[14] C. A. Severiano, P. C. L. Silva, H. J. Sadaei and F. G. Guimarães, (2017), "Very short-term solar forecasting using fuzzy time series," IEEE International Conference on Fuzzy Systems (FUZZ-IEEE), pp. 1-6, doi: 10.1109/FUZZ-IEEE.2017.8015732.

[15] https://apps.ecmwf.int/datasets/data/interim-full-daily/levtype=sfc/

[16] Rajaonarisoa, H.A., Ramahazosoa, I.P., \& Ratiarison, A.A., (2020), "Spatial and temporal variabilty of precipitation in southern of Madagascar", International Journal of Advance Research and Innovative Ideas in Education, Vol. 6, pp 325-338.

[17] Srikanth, S., Sudha, K. R., \& Raju, Y. B, (2016), "Fuzzy load frequency controller in deregulated power environment by principal component analysis".Int. J. Fuzzy Logic Syst, 6(1),13-30.

[18] Jackson, J.E., (1991),“A User's Guide to Principal Components ”, John Wiley \& Sons, New York, 43. (https://doi.org/10.1002/0471725331)

[19] Jolliffe, I., (2002), "Principal Component Analysis". 2nd Edition, Springer, New York

[20] Peres-Neto, P.R., Jackson, D.A. and Somers, K.M., (2005), "How Many Principal Components? Stopping Rules for Determining the Number of Non-Trivial Axes Revisited". Computational Statistics and Data Analysis, 49, 974-997. (http://dx.doi.org/10.1016/j.csda.2004.06.015)

[21] Xingdong Chen, Chao Chen, Li Jin, (2011), "Principal Component Analyses in Anthropological Genetics", Advances in anthropology, vol 1, №2, 9-14, DOI : 10.4236/aa.2011.12002

[22] Sidharth Prasad Mishara et al, (2017), "Multivariate Statistical Data - Principal Component Analysis (PCA)", International Journal of livestockresearch, pp 60-78

[23] Laurens Van Der Matten, Geoffrey Hinton, (2008), "Visualizing data using t-sne", Journal of machine learning research, vol $1:$ pp 1-25

[24] Kobak, D., Berens, P., (2019), "The art of using t-SNE for single-cell transcriptomics". Nat Commun 10, 5416, doi:10.1038/s41467-019-13056-X

[25] L.J.P. van der Maaten.,(2014), “Accelerating t-SNE using Tree-Based Algorithms”. Journal of Machine Learning Research 15(Oct):3221-3245.

[26] L.J.P. van der Maaten, (2009), "Learning a Parametric Embedding by Preserving Local Structure". In Proceedings of the Twelfth International Conference on Artificial Intelligence \& Statistics (AISTATS), JMLR W\&CP 5:384-391.

[27] Youguo Li, Haiyan Wu, (2012), “A clustering Method Based on K-Means Algorithme”, International Conference on Solid State Devices and Materials Science, Physics Procedia 25 : 1104-1109, DOI: 10.1016/j.phpro.2012.03.206

[28] Chunfei Zhang, Zhiyi Fang.,(2013),“An Improved K-means Clustering Algorithme”, Journal of Information \& Computational Science, Volume 10, No. 1, pp :193-199.Retrieved from https://pdfs.semanticscholar.org/f02a/05ec0dcec24620419de5f5261be64b73945e.pdf

[29] Aguiar, R. A., \& Belardi, A. A, (2013),"Predictive evaluation of the stock portfolio performance using Fuzzy C-means Algorithm and Fuzzy Transform”, International Journal of Fuzzy logic systems (IJFLS), 3(2).

[30] J Nayak, B Naik, HS Behera, (2015), "Fuzzy C-means (FCM) clustering algorithm: a decade review from 2000 to 2014", Computational intelligence in data mining, Vol.2, 133-149, DOI: 10.1007/97881-322-2208-8_14

[31] Gokten, P.O., Baser, F. and Gokten, S., (2017), "Using fuzzy c-means clustering algorithm in financial health scoring", Audit Financiar, vol. XV, nr. 3(147)/2017, pp. 385-394, DOI: 10.20869/AUDITF/2017/147/385, (http://dx.doi.org/10.20869/AUDITF/2017/147/385)

[32] Aybükë Oztürk, Stéphane Lallich, Jérôme Darmont., (2018), “A visual quality index for fuzzy CMeans",14th International Conference on Artificial Intelligenc eApplications and Innovations, 
International Journal of Fuzzy Logic Systems (IJFLS) Vol.10, No.3/4, October 2020

Rhodes, Greece. pp.546-555, 10.1007/978-3-319-92007-8_46. hal-01727426. (https://hal.archivesouvertes.fr/hal-01727426)

[33] Wang, C., Fang, H., Kim, S., Moormann, A., Wang, H., (2015), “A New Integrated Fuzzifier Evaluation and Selection (NIFEs) Algorithm for Fuzzy Clustering”. Journal of Applied Mathematics and Physics, 3, 802-807. doi: 10.4236/jamp.2015.37098.

[34] X. Li, X. Lu, J. Tian, P. Gao, H. Kong et al., (2009), “Application of fuzzy c-Means clustering in data analysis of metabolomics", Analytical Chemistry, vol.81, issue.11, pp.4468-4475,DOI : 10.1021/ac900353t

[35] Balafar, M.A., (2014), "Fuzzy C-mean based brain MRI segmentation algorithms”, Artif Intell Rev, pp41: 441.( https://doi.org/10.1007/s10462-012-9318-2)

[36] Dunn, J. C.,(1973), “Well - separated clusters and optimal fuzzy partitions”. Journal of Cybernetics (published 1974). 4 (1): 95-104. Doi:10.1080/01969727408546059. ISSN 0022-0280

[37] Dunn, J. C., (1973), “A Fuzzy Relative of the ISODATA Process and Its Use in Detecting Compact Well-Separated Clusters", Journal of Cybernetics. 3 (3): 32-57. doi:10.1080/01969727308546046

[38] Trauwaert, E., (1988),“On the meaning of Dunn's partition coefficient for fuzzy clusters”. Fuzzy Sets and Systems, 25(2), 217-242. doi:10.1016/0165-0114(88)90189-3

[39] J. C. Bezdek and N. R. Pal, "Cluster validation with generalized Dunn's indices," Proceedings 1995 Second New Zealand International Two-Stream Conference on Artificial Neural Networks and Expert Systems, Dunedin, New Zealand, 1995, pp. doi: 10.1109/ANNES.1995.499469

[40] Pakhira, Malay K.; Bandyopadhyay, Sanghamitra; Maulik, Ujjwal,(2004),"Validity index for crisp and fuzzy clusters". Pattern Recognition. 37 (3): 487-501. doi:10.1016/j.patcog.2003.06.005.

[41] Havens, T.C., Bezdek, J.C., Keller, J.M., \& Popescu, M.,(2008), “Dunn’s cluster validity index as a contrast measure of VAT images". 19th International Conference on Pattern Recognition, 1-4.

[42] Petrônio C., (2019), "Scalable models for probabilistic forecasting with fuzzy time series", Final thesis presented to the Graduate Program in Electrical Engeneering of the federal University of Minas Gerais in partial fullfillment of requirements for the degree of Doctor in ElectricalEngineering, retrieved from https://repositorio.ufmg.br/bitstream/1843 /30040/1/ Final_Thesis.pdf

[43] C. A. Severiano, P. C. L. Silva, H. J. Sadaei and F. G. Guimarães, (2017), "Very short-term solar forecasting using fuzzy time series", IEEE International Conference on Fuzzy Systems (FUZZ-IEEE), Naples, 2017, pp. 1-6, doi: 10.1109/FUZZ-IEEE.2017.8015732.

[44] Huarng, Kun-Huang, (2001), "Effective lengths of intervals to improve forecasting in fuzzy time series”,Fuzzy Sets and Systems, 123. 387-394. 10.1016/S0165-0114(00)00057-9.

[45] Cheng et al., (2006), «Entropy-based and trapezoid fuzzification-based fuzzy time series approach for forecasting IT project cost », Technological Forecasting and Social Change, Vol. 73, pp 524-542

[46] Li, S. T., Cheng, Y. C. and Lin, S. Y., (2008), "A FCM Based deterministic forecasting model for fuzzy time series", Computers and Mathematics with Applications, Vol. 56 (12), pp 3052-3063.

[47] Hsuan-Shih Lee \& Ming-Tao Chou, (2004), «Fuzzy forecasting based on fuzzy time series », International Journal of Computer Mathematics, Vol. 81 :7, pp 781-789.

[48] https://towardsdatascience.com/ a-short-tutorial-on-fuzzy-time-series-part-ii-with-an-case-study-onsolar-energy-bda362ecca6d 